\title{
Role of FNAC in the diagnosis of cysticercosis
}

\author{
Parakh R ${ }^{1}$, Gupta $S^{2}$, Singh $S^{3}$, Garewal $J^{4}$, Rajput $\mathbf{R}^{5}$, Vashsit $S^{6}$ \\ ${ }^{1}$ Dr Richa Parakh, Assistant Clinic, Coordinator; Pathologist, SPRIM, Singapore, ${ }^{2}$ Dr Sumit Gupta, Assistant Professor; \\ Department of Pathology, NIMS Medical college Jaipur, ${ }^{3}$ Dr Swati Singh , Junior Resident, Department of Pathology, \\ NIMS Medical College Jaipur, ${ }^{4}$ Dr Jaydeep Garewal, Junior Resident; Department of Pathology, NIMS Medical College \\ Jaipur, ${ }^{5}$ Dr Rashmi Rajput, Junior Resident; Department of Pathology, NIMS Medical College Jaipur, ${ }^{6}$ Dr Shelly Vashist, \\ Junior Resident; Department of Pathology, NIMS Medical College Jaipur, India
}

Address for Correspondence: Dr Sumit Gupta, Email: drsumitpatho@yahoo.com

\begin{abstract}
Background and Objectives: Cysticercosis is a common tropical disease. Human cysticercosis is caused by the dissemination of the embryo of Taenia solium in the intestine via the hepatoportal system to the tissues and organs of the body. The organs most commonly affected are the subcutaneous tissues, skeletal muscles, lungs, brain, eyes, liver, and occasionally the heart, thyroid, and pancreas. Fine needle aspiration cytology (FNAC) plays an important role in prompt recognition of this disease. Aims: To study the role of FNAC in the diagnosis of cysticercosis. Methods: Fifteen patients with subcutaneous and intramuscular nodules, who were clinically diagnosed as lipoma, neurofibroma, lymphadenitis, cold abscess, epidermal inclusion cyst, sebaceous cyst, fibroadenoma and cysticercosis were included in the present study. Results: In $4(26.6 \%)$ cases, a definitive diagnosis of cysticercosis was obtained in the form of fragments of parasite bladder wall and, biopsy confirmed the diagnosis. In the rest 11 (73.3\%) cases, larval fragments could not be identified on the aspirates and the diagnosis of parasitic inflammation was suggested on the basis of other cytomorphological findings. Follow-up biopsy confirmed the diagnosis of cysticercosis. Conclusions: Cysticercosis is continuing to be a major health problem in developing countries. Fine needle aspiration cytology (FNAC) is cost effective and simple procedure. The cytological diagnosis is quite straightforward in cases where the actual parasite structure is identified in the smears. However, in other cases, presence of eosinophils, histiocytes, a typical granular dirty background are the features which should always alert the pathologist to this possibility.
\end{abstract}

Key words: Cysticercosis, Taenia Solium, Fine needle aspiration cytology.

\section{Introduction}

Cysticercosis is a parasitic infection with the larval stage of Taenia solium [1-4]. T. solium is a zoonotic cestode which has a complex life cycle [5]. It is seen as cysts more commonly in the brain, muscle, heart and the orbit $[1,6-8]$. Humans harbour the tapeworm in the gut and act as the definitive host without significant symptoms [9]. The life span of adult tapeworm is few years during which they produce millions of eggs which are intermittently released in the environment with the faeces [10]-[12].

Humans and pigs acquire cysticercosis by ingesting $\mathrm{T}$. solium eggs by the faeco-oral route [5]. After the

Manuscript received: $15^{\text {th }}$ Feb 2016

Reviewed: $25^{\text {th }}$ Feb 2016

Author Corrected: $3^{\text {rd }}$ March 2016

Accepted for Publication: $11^{\text {th }}$ March 2016 ingestion, embryos contained in the eggs are released, cross the intestinal mucosa and reach the circulatory system and dispersed in the body producing cysts mainly in the central nervous system (CNS) and in striated muscles [5].

Humans can acquire cysticercosis ingesting $T$. solium eggs released by them selves (auto infestation) or carrier of tapeworm in close contact or handling food preparation. [13], [14]. Neurocysticercosis (NCC) is caused by localization of cyst in the brain [5].

It is endemic in America, Africa and Asia and linked to low socioeconomic status, ignorance, absence of suitable diagnostic and management ability and poor 
standards of hygiene [15]. In India, it is more common in northern parts.

The preoperative diagnosis of cysticercosis can be made by radiological tools and serological tests like ELIS, Radioimmunoassay, Complement Fixation test. Radiological scans though sensitive in diagnosing cysticercosis; especially when the parasite involves the nervous system are not cost effective nor provide final diagnosis. Positive serological tests are of value but possibility of false negative exists. False positivity is expected with cross reactivity or previous parasitic infestation with other helminths.

Fine needle aspiration cytology (FNAC) is now available as an important method for the diagnosis of subcutaneous cysticercosis. The histopathological examination of the excised tissue is the gold standard for the diagnosis.

The present study was done to analyse the

\section{Results}

The study included 15 patients in the age group 8-65 years. Among 15 patients, 6 were females and 9 were males. Out of all patients, only two complaint of multiple nodules while rest presented with single, slow growing, painless, slowgrowing nodule of variable sizes. 4 cases presented with neck swelling, 5 with arm swelling and 3 with abdominal wall swelling, 1with swelling axilla, 1 with swelling cheek and 1 with swelling breast (Table 1). On clinical examination, most of lesions were nodular, non tender and soft to firm in consistency.

Provisional clinical diagnosis of Cysticercosis was made in only 2 cases, while the majority were clinically misdiagnosed as lipoma, neurofibroma, reactive lymphadenitis, tuberculous lymphadenitis, sebaceous cyst, fibroadenoma and benign tumour (Table 1). The aspirated material consisted of few drops to $4 \mathrm{~mL}$ fluid of variable consistency including clear fluid with or without granular deposit in 8 cases, purulent fluid in 5 cases, and blood-mixed fluid in 2 cases. No post procedure complication were observed.

In 4 cases, a definite evidence of cysticercosis was observed. The evidence on cytology was bladder wall fragments of cysticercus although the cytomorphology was not exactly the same in all cases (Figure 1-A). None of them showed hooklets or scolex. Follow-up biopsy confirmed the diagnosis (Figure 2). All these cases showed varying proportion of inflammation with or without granuloma or giant cells.

In the rest 11 cases, the cytological findings were in favor of a parasitic cyst; however, no parasite could be seen. None of these cases showed hooklets or scolex on cytology. The cytology of these cases revealed mixed inflammatory infiltrate, macrophagess, multinucleated giant cells, and non caseating epithelioid granuloma in a dirty granular background (Figure 1-B).These cytological findings suggested a parasitic cystic infestation and excision was advised. The histopathological findings confirmed the diagnosis of cysticercosis.

In this study, all cases of parasitic lesions showed mixed inflammatory response ranging from few histiocytes to diffuse mixed inflammatory cells.Presence of eosinophils were seen in only 7. Out of the 15 cases while lymphocytes, histiocytes, neutrophil, foreign body giant cells, and epithelioid granuloma were seen in 3 ,6 , 3 , 2 and 1 cases, respectively. Dirty granular background was seen in 7 cases (Table 2). 
Table 1: Site of involvement and clinical diagnosis in 15 cases included in the present study

\begin{tabular}{|c|c|c|}
\hline S. No. & Site & Clinical Diagnosis \\
\hline 1. & Right arm & Lipoma \\
\hline 2. & Right cheek & Sebaceous cyst \\
\hline 3. & Left neck & Reactive Lymphadenitis \\
\hline 4. & Right arm & Neurofibroma \\
\hline 5. & Abdominal wall & Benign tumor \\
\hline 6. & Left arm & Benign tumor \\
\hline 7. & Abdominal wall & Cysticercosis \\
\hline 8. & Right neck & Tuberculous lymphadenitis \\
\hline 9. & Left Breast & Fibroadenoma \\
\hline 10. & Left arm & Neurofibroma \\
\hline 11. & Abdominal wall & Benign tumor \\
\hline 12. & Right neck & Reactive lymphadenitis \\
\hline 13. & Left neck & Reactive Lymphadenitis \\
\hline 14. & Right axilla & Lipoma \\
\hline 15. & Right arm & Cysticercosis \\
\hline
\end{tabular}

Table 2: Clinical Diagnosis and No. of cases

\begin{tabular}{|c|l|c|}
\hline S. No. & Clinical Diagnosis & No. of cases \\
\hline 1. & Lipoma & 2 \\
\hline 2. & Sebaceous Cyst & 3 \\
\hline 3. & Reactive Lymphadenitis & 2 \\
\hline 4. & Neurofibroma & 2 \\
\hline 5. & Cysticercosis & 3 \\
\hline 6. & Benign Tumor & 1 \\
\hline 7. & Tuberculous Lymphadenitis & 1 \\
\hline 8. & Fibroadenoma & \\
\hline
\end{tabular}


Table 3: Cytological features in 15 cases included in present study

\begin{tabular}{|c|l|c|}
\hline S. No. & Cytological Findings & No. of Cases \\
\hline 1. & Fragments of bladder wall of Cysticercus & 4 \\
\hline 2. & Eosinophils & 0 \\
\hline 3. & Hooklets & 3 \\
\hline 4. & Lymphocytes & 6 \\
\hline 5. & Histiocytes & 3 \\
\hline 6. & Neutrophils & 2 \\
\hline 7. & Foreign body Giant cells & 1 \\
\hline 8. & Epithelioid granuloma & 7 \\
\hline 9. & Dirty granular background & \\
\hline
\end{tabular}
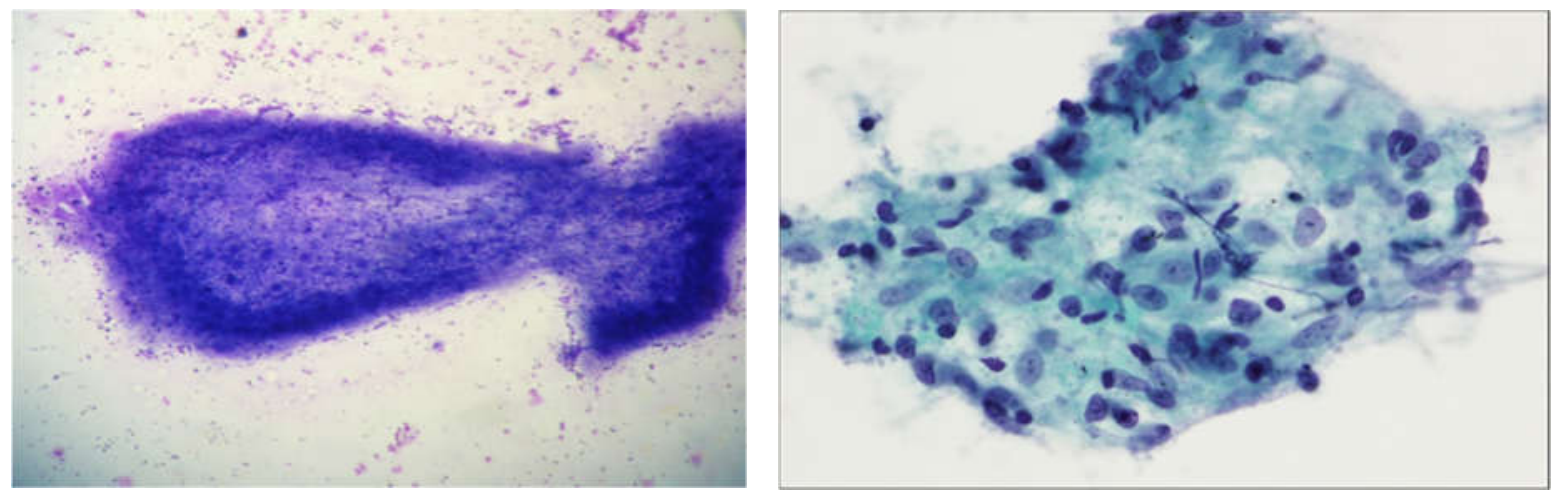

Figure 1: (A) Cytological smear showing bladder wall fragment of cysticercuscellulosae surrounded with inflammatory cells. (B) Aspirate showing a cluster of epithelioid histiocytes. (Papanicolaou stain).

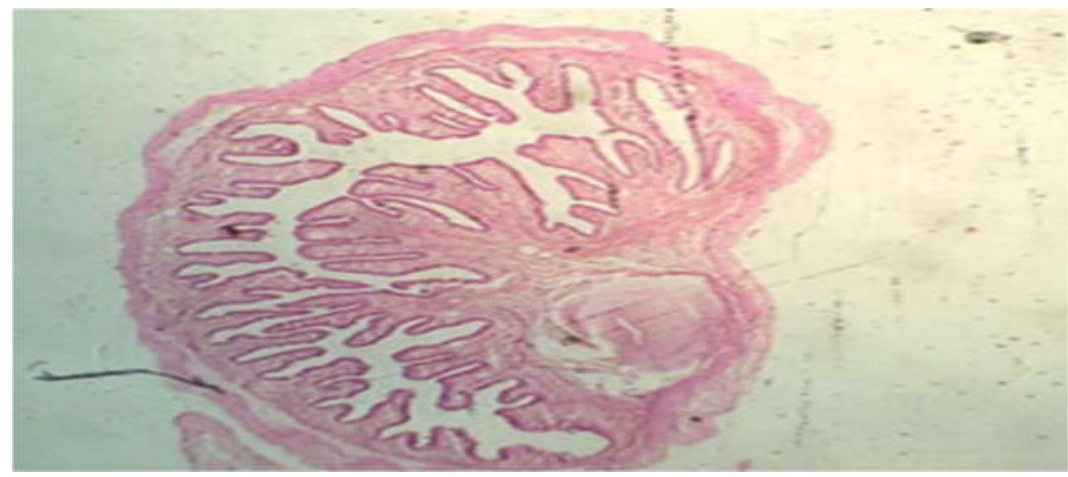

Figure 2: Photomicrograph of tissue sections showing cysticercus larva enclosed in a thin fibrous cyst wall $(\mathrm{H}$ and $\mathrm{E})$

\section{Discussion}

Cysticercosis in humans is an ancient disease and has even been detected in Egyptian mummies by paleoparasitologists [16]. Cysticercosis is the larval stage infection of the cestode Taenia solium. The 
definitive host are only humans and can also behave as intermediate hosts by ingestion of raw or poorly cooked vegetables or water contaminated with eggs or pork infested with larvae [17]. Cysticercosis is also common in vegetarians due to absence of proper sanitation standards in developing countries [18].

Fully developed cysticerci are opalescent, milky white cysts, eongated to oval $\mathrm{m} / \mathrm{s}$ approximately $1 \mathrm{~cm}$ in full length. The cyst contains fluid and a single invaginated scolex. The scolex has a rostellum, 22-30 small hooklets and four suckers. The wall of the cyst is multilayered, 100-200 $\mu \mathrm{m}$ thick and covered by microvilli.

The cysticercosis infection presents most commonly as intramuscular or subcutaneous palpable nodule [19]. Most of these cases are clinically misdiagnosed as benign or malignant soft-tissue tumor or lymphadenitis depending on the site [20]. The diagnostic role of FNAC in cysticercosis was first emphasized by Kung et al. in 1989 [21]. Since then FNAC plays an important role in assessing subcutaneous or muscle nodules caused by parasites [20]. The cytomorphological identification of larvae in cytological smears by different observers has widened the diagnostic utility of FNAC in skin nodules [22, 23 and 24].

Essential for the cytodiagnosis of cysticercosis is look for the fragments of parasite including its hooklets and bladder wall. The cytomorphology of cysticercosis varies from viable cysts through calcified to necrotic lesions. The most common finding in viable cysts is delicate fragments of bladder wall with tiny, parasitic nuclei in a clear, acellular background. The aspiration findings reveal fragments of bladder wall Aspirates of necrotic lesions may contain fragments of bladder wall, invaginated portions, including calcerous corpuscles and detached single hooklets. Parasitic fragments may comprise bluish, fibrillary structures, sometimes with clustering, thrown tegument into rounded wavy folds, calcospherules, scolex with hooklets, and hyaline membrane surrounding it [25-27].

The physical factors such as the firm non expansile nature of the host tissue may limit the parasite growth and start inflammatory response of the host. The presence of eosinophils, neutrophils, palisading histiocytes, giant cells, and atypical granular dirty background in an aspirate from a subcutaneous nodule should suggest a differential of parasitic infestation. Nonetheless, still in some cases of cysticercosis, none of these features may be found, and the inflammation may differ [20]. Viable cysticerci may not cause any inflammation but when their degeneration occurs, there is inflammatory cells response, associated with foreign body giant cell reaction and variable granuloma. The viable cyst or calcified and necrotic lesions all have distinctive cytological features. The viable cyst aspirate is clear fluid and reveal bladder wall fragments in a clear acellular background. Finding an entire scolex in FNA is a rare event [28]. None of our cases showed hooklets or scolex on cytology.

The most common cause of intramuscular or subcutaneous palpable parasitic nodule is most commonly due to cysticerci. The similar clinical presentation by other parasites includes larval form of tapeworm and Multiceps and Spargana, larva of Spirometra Mansonoides [29]. Hydatid cyst caused by the larva of Echinococcus Granulosus can also occur in the subcutaneous tissue as an unusual presentation [30]. Cytomorphological details of the aspirate help to differentiate each other. The suckers and hooklets are present in Cysticerci and coenuri while absent in spargna. Multiple protoscolices are seen in Coenures while cysticerci has only one scolex, which is rarely seen in cytological findings [29]. Bladder wall is thin and membranous in cysticerci while it is lamellated and thicker in a hydatid cyst. The single scolex of cysticerci in aspirate is differentiated by multiple scolices of hydatid cyst.[29].

\section{Conclusion}

FNAC has emerged as an easy, quick, reliable, and sensitive diagnostic tool in identifying parasitic cyst. In FNAC smears if we are able to demonstrate parasitic bladder wall, tegument fragments, hookletsandcalcareous corpuscles, it helps to give definitive diagnosis and avoid open excision biopsy in many cases.

Conflicts Of Interest: The authors declare that there is no conflict of interests regarding the publication of this paper.

Funding: Nil, Conflict of interest: None. Permission of IRB: Yes

\section{References}

1. Mittal A, Gupta S, Gupta S, Mehta V. Subcutaneous and intramuscular cysticercosis: high-resolution 
sonography. Indian J DermatolVenereolLeprol. 2009 Sep-Oct;75(5):515-6. doi: 10.4103/0378-6323.55404.

2. Craig P, Ito A. Intestinal cestodes. Curr Opin Infect Dis. 2007 Oct;20(5):524-32.

3. García HH, Gonzalez AE, Evans CA, Gilman RH; Cysticercosis Working Group in Peru. Taenia solium cysticercosis. Lancet. 2003 Aug 16;362(9383):547-56.

4. King CH. Cestodes (tapeworms). In: Mandell GL. (ed.) Principles and practice of infectious diseases. 6th ed. Philadelphia: Elsevier Churchill Livingstone; 2005, p. 3289 .

5. Garcia HH, Del Brutto OH. Taenia solium cysticercosis. Infect Dis Clin North Am. 2000 Mar;14(1):97-119, ix.

6. Kraft R. Cysticercosis: an emerging parasitic disease. Am Fam Physician. 2007 Jul 1;76(1):91-6.

7. Smiti S, Sripathi H, Naik L. Unusual location of cysticercus lesions in soft tissue-report of three cases. Indian J Radiol Imaging 2003; 13: 157-158.

8. Mamere AE, Muglia VF, Simão GN, Belucci AD, Carlos dos Santos A, Trad CS, Takayanagui OM. Disseminated cysticercosis with pulmonary involvement. J Thorac Imaging. 2004 Apr;19(2):10911.

9. Pawlowski Z, Allan J, Sarti E. Control of Taenia solium taeniasis/cysticercosis: from research towards implementation. Int $\mathrm{J}$ Parasitol. 2005 Oct;35(1112):1221-32.

10. Allan JC, Velasquez-Tohom M, Garcia-Noval J, Torres-Alvarez R, Yurrita $\mathrm{P}$, et al. Epidemiology of intestinal taeniasis in four, rural, Guatemalan communities. Ann Trop Med Parasitol 1996 Apr:90(2): $157-165$.

11. Allan JC, Velasquez-Tohom M, Torres-Alvarez R, Yurrita P, Garcia-Noval J. Field trial of the coproantigen-based diagnosis of Taenia solium taeniasis by enzyme-linked immunosorbent assay. Am J Trop Med Hyg. 1996 Apr;54(4):352-6.

12. García HH, Gilman RH, Gonzalez AE, Verastegui M, Rodriguez S, Gavidia C, Tsang VC, Falcon N, Lescano AG, Moulton LH, Bernal T, Tovar M;
Cysticercosis Working Group in Perú. Hyperendemic human and porcine Taenia solium infection in Perú. Am J Trop Med Hyg. 2003 Mar;68(3):268-75.

13. Bourke GJ, Petana WB. Human Taenia cysticercosis: a bizarre mode of transmission. Trans R Soc Trop Med Hyg. 1994 Nov-Dec;88(6):680.

14. Schantz PM, Moore AC, Muñoz JL, Hartman BJ, Schaefer JA, Aron AM, Persaud D, Sarti E, Wilson M, Flisser A. Neurocysticercosis in an Orthodox Jewish community in New York City. N Engl J Med. 1992 Sep 3;327(10):692-5.

15. Willingham AL 3rd, Engels D. Control of Taenia solium cysticercosis/taeniosis. Adv Parasitol. 2006;61:509-66.

16. R. Kraft, "Cysticercosis: an emerging parasitic disease," American Family Physician, vol. 76, no. 1, pp. 91-98, 2007.

17. F. Bruschi, M. Masetti, M. T. Locci, R. Ciranni, and G. Fornaciari, "Short report: cysticercosis in an Egyptian mummy of the late ptolemaic period," American Journal of Tropical Medicine and Hygiene.2006 ,74,598-99

18. Kraft R. Cysticercosis: an emerging parasitic disease. Am Fam Physician. 2007 Jul 1;76(1):91-6.

19. Suchitha S, Vani K, Sunila R, Manjunath GV. Fine needle aspiration cytology of cysticercosis-a case report.

Case Rep Infect Dis. 2012;2012:854704. doi: 10.1155/2012/854704. Epub 2012 Jul 18.

20. Sawhney M, Agarwal S. Cysticercosis: hooked by a hooklet on fine needle aspiration cytology-a case report. Case Rep Infect Dis. 2013;2013:315834. doi: 10.1155/2013/315834. Epub 2013 Aug 19.

21. Kung IT, Lee D, Yu HC. Soft tissue cysticercosis. Diagnosis by fine-needle aspiration. Am J Clin Pathol. 1989 Dec;92(6):834-5.

22. Vuong PN. Fine needle aspiration cytology of subcutaneous cysticercosis of the breast. Case report and pathogenic discussion. Acta Cytol. 1989 SepOct;33(5):659-62. 
23. Kung IT, Lee D, Yu HC. Soft tissue cysticercosis. Diagnosis by fine-needle aspiration. Am J Clin Pathol. 1989 Dec;92(6):834-5.

24. Verma K, Kapila K. Fine needle aspiration diagnosis of cysticercosis in soft tissue swellings. Acta Cytol. 1989 Sep-Oct;33(5):663-6.

25. Nigam S, Singh T, Mishra A, Chaturvedi KU. Oral cysticercosis--report of six cases. Head Neck. 2001 Jun;23(6):497-9

26. Kamal MM, Grover SV. Cytomorphology of subcutaneous cysticercosis. A report of 10 cases.

Acta Cytol. 1995 Jul-Aug;39(4):809-12.

27. V. K. Arora, K. Gupta, N. Singh, and A. Bhatia,

"Cytomorphologic panorama of cysticercosis on fine needle aspiration: a review of 298 cases," ActaCytologica 1994 May-Jun;38(3):377-80.

28. N. Singh, V. K. Arora, and A. Bhatia, "Are all subcutaneous parasitic cysts cysticercosis?" ActaCytol 2006 Jan-Feb;50(1):114-5.

29. Handa U, Garg S, Mohan H. Fine needle aspiration in the diagnosis of subcutaneous cysticercosis. Diagn Cytopathol. 2008 Mar;36(3):183-7. doi: 10.1002/dc.20792.

30. Singh N, Arora VK, Bhatia A. Are all subcutaneous parasitic cysts cysticercosis? Acta Cytol. 2006 JanFeb;50(1):114-5.

\section{How to cite this article?}

Parakh R, Gupta S, Singh S, Garewal J, Rajput R, Vashsit S. Role of FNAC in the diagnosis of cysticercosis. Int J Med Res Rev 2016;4(3):407-413. doi: 10.17511/ijmrr.2016.i03.22 